\title{
Katoliikliku sakraalse materiaalsuse postmodernistlikud jooned
}

\author{
Leonard Norman Primiano
}

Mõned aastad tagasi helistas mulle mu endine õpilane, kes elas Newfoundlandil Corner Brooki linnas. Ta oli kuulanud mu rahvausundi kursust, kui ma olin külalisprofessor Newfoundlandi Memorial University rahvaluule õppetoolis. Mäletades minu käsitlust tänapäevasest katoliku pühakute austamisest, esitas ta mulle palve. Kas ma saaksin osta ja talle saata odava Püha Joosepi, tööliste ja perekonna kaitsepühaku kuju?

Kuigi ta elas provintsi suuruselt teises linnas, saarel, kus on suur katoliku kogukond, oli tal raskusi selle religioosse eseme leidmisega, mida tema isa pidas ülioluliseks nende kodu mahamüümisel. Mu õpilane ütles, et tema isa oli kuulnud, kuidas inimestel õnnestus majanduslikult rasketel 1990. aastatel nii äri- kui eluruume edukalt maha müüa, kui nad matsid kõnealuse hoone tagaaeda Püha Joosepi kuju. Pühaku kuju matmise ja säilitamise juhendeid (matta oma pakendis, pea alaspidi või lamamas vasakul küljel, maja ette või taha, näoga maja või tänava poole või sildi «Müügiks» kõrvale) oli õpilase isale räägitud ja interpreteeritud erinevates variantides, kuid kohustusliku osana leidus seal alati õpetus, mille kohaselt kuju tuli pärast hoone müümist üles kaevata ja uues kodus või äris tähtsale kohale asetada.

Seegi majaomanik oli veendunud tegevuse efektiivsuses ja soovis kuju enda hüvanguks kasutada (vt ka Clark 1990; Pacelle 1990). Ta järgis igivana kristlikku traditsiooni võtta pühad esemed, nagu märtrite ja pühakute reliikviad, ja kasutada neid igapäevaelu «sakramentaliseerimiseks» (Brown 1981). Kristlased integreerivad jätkuvalt igapäevaellu kristlikke kujutelmi ja sümboleid väljendavat materiaalset kultuuri ja seda alates käsitsivalmistatud esemetest trükikirjanduse ja masstoodanguni. Religioosset materiaalset kultuuri ostetakse ja kingitakse jätkuvalt, et asetada seda koju, töökohale või transpordivahenditesse või kanda endaga kaasas (Lepovitz 1991; Spamer 1930). Seda traditsiooni on lihtne jälgida, kui olla välitöil Põhja-Ameerika usklike seas või regionaalsetes ja etnilistes kogukondades (Cartwright 1981; Cooper \& Sciorra 1994; Cosentino 1995; Dewhurst et al. 1983; Flores-Peña \& Evanchuk 1994; Gizelis 1971; Halle 1993; Lange 1974; Lessard 1981; Milspaw 1986; Morgan 1998; Orsi 1985, 1996; Pocius 1986; Sciorra 1989, 1993; Shaner 1961, 1972; Teske 1973, 1980, 1985; Turner 1982, 1983, 1990; Turner \& Seriff 1987; Vlach 1989; Yoder 1988, 1990; Yoder \& Graves 1989).

Ma valisin oma panuseks selles kogumikus religioosse materiaalse kultuuri rõhutamise, $\mathbf{1}$ sest endiselt on võimalik uurida Ameerika religiooni ajalugu iialgi katsumata ainsatki artefakti, nägemata ühtegi pilti või isegi külastamata ühtegi paika, mis on seotud selle diskussiooni subjektideks olevate inimeste elava usundiga. Samuti on võimalik lugeda tekste religioonist Ameerikas, nägemata kunagi ühegi religioosse objekti pilti või kohtamata arutelu selle üle. Samal ajal on Ameerika kiriklik kunst ja arhitektuur üks osa materiaalse kultuuri uurimisest, Ameerika religioosne loovus sage käsitlusalune (Dillenberger 1984; Williams 1988, 1997). Sellised uurimused on suurepäraseks aluseks religioossete institutsioonide ameerikaliku materiaalse eneseväljenduse mõistmiseks, kuid materjali esitatakse neis normatiivsest kiriklikust vaatekohast, mitte inimeste uskumuste avaldustena. Alles hiljuti on avaldatud mõned ajaloolised uurimused Ameerika religiooni materiaalsest kultuurist ja litograafiast, milles käsitletakse ameeriklaste poolt valmistatud ja kasutatud religioosseid objekte (McDannell 1995; Morgan 1996, 1998). Raamatus Material Christianity käsitleb Colleen McDannell «kristliku kaubanduse» vaatekohast Ameerika protestantlikke religioosseid kaupu müüvaid 
katalooge ja raamatupoode, kuid ta ei pööra erilist tähelepanu poodidele, mis müüvad katoliiklikke religioosseid kaupu.

Minu huvi katoliikliku materiaalse kultuuri vastu üldiselt ja eriti Püha Joosepi vastu viis mind mitmesse kaubandusettevõttesse Philadelphias. Külastasin muuseumi- ja kirikupoode, mis müüsid gooti stiilis katoliiklikke artefakte - kõike, alates keskaegsetest gargoüülidest ja renessansi inglikujudest kuni köögimagnetiteni ja toonitud klaasist katedraalikunsti replikateni. Ma leidsin rahvakunstipoode, mis müüsid autentseid Mehhiko, New Mexico ja Puerto Rico santosid (antikvaarsed ja tänapäevased puust voolitud kujukesed pühakutest ja ristilöödud Kristusest), retablosid (plekile maalitud pildid pühakutest või isiklikest imejuhtumitest) ja tänapäevast turistidele mõeldud religioosset kunsti (kipsist, savist või paberist valmistatud kujukesi Guadalupe Jumalaemast, Ameerika patroonist, mis asetseb plekist või puust pühakojakeses) (Briggs 1989; Durand \& Massey 1995; Giffords 1992; Kalb 1994). Oli ka retrokatoliiklikke poode, mis müüsid masstootmises olevaid katoliiklusest inspireeritud asju (näiteks Nunzilla - üleskeeratav mängununn, kes puhub käies tulesädemeid, poksiv nunn - poksikinnastega nunna kuju) ja veel palju muid katoliiklikke objekte käesoleva sajandi esimesest kuuekümnest aastast (kaasa arvatud kipsreproduktsioone või kujukesi Maarja ilmutustest Lourdes'is ja Fátimas).

Ma leidsin ka afrokariibi botanica'sid, mis müüsid pühakute kujutistega küünlaid, plastikust ja kipsist kujukesi, maagilise mõjuga õlisid ja mõnikord pakkusid tagaruumis kokkusaamist lugeja ja soovitajaga (Borrello \& Mathias 1977; Murphy 1988: 39-48). Tihti kattusid botanica'd nii esemete kui klientuuri poolest ka New Age'i, paganate, wicca poodidega, mis pakuvad suures valikus materiaalseid kujutisi (neoliitiline jumalanna Euroopast, druiidide ja keldi sümbolid, antiik-kreeka ja -rooma panteon, Ameerika põliselanike tootemid, hinduismi ja budismi kujud, roomakatoliku ikonograafia ja afrokariibi ohvripildid). Müüakse ka küünlaid, õlisid, kivisid ja kristalle, raamatuid ja perioodikat, trumme ja kõristeid, peekreid ja anumaid, nii kandmiseks kui ka altarile asetamiseks mõeldud pentagramme ning meditatiivset ja rituaalset muusikat (vt Adler 1986, kes tutvustab ülevaatlikus käsitluses sellistes poodides leiduvat wicca ja paganlikku perioodikat, samuti ka klientuuri kattumisi ja erinevusi nende poodide vahel). Üldiselt külastavad inimesed nii botanica'sid kui selliseid metafüüsilisi keskusi üldise huvi ja uudishimu tõttu, aga ka sünkretistlikust huvist saada osa ususüsteemist, mida need esindavad.

Sama võib öelda ka traditsiooniliste roomakatoliku religioosse kauba poodide kohta, kus võib näha tänapäeva ameeriklasi, kes identifitseeruvad roomakatoliku traditsioonidega. Selliseid poode külastavad konservatiivsed, restauratsioonilised ja progressiivsed katoliiklased, samuti ka katoliiklusest mõjutatud või sellest huvituvad inimesed, nagu näiteks voodoo, santeria jms järgijad.

Retk odava Püha Joosepi kuju järele viis mind lõpuks Püha Juuda poe juurde Havertownis Pennsylvanias, mida reklaamiti peapiiskopkonna ajalehes The Catholic Standard and Times kui «suurimat religioossete kaupade poodi». See pood asub etniliselt kirju Philadephia linna keskklassi äärelinnas, mis on endiselt tuntud oma konservatiivse katoliikluse poolest, ja on osa kuuekaupluselisest poodide ketist, mida tuntakse kui «Saint Jude Shop Inc.», mida üks selle perekonna liikmetest Mark G. DiCocco kirjeldas kui «korporatsiooni, mille tegutsemise põhimõtteks on religioossete artiklite, raamatute ja kirikutarvete jae- ning hulgimüük». Selle poe odavate Püha Joosepi kujude varu oli otsa lõppenud ja ma pidin sinna ostu sooritamiseks uuesti tagasi pöörduma. Edasised käigud sinna äratasid minus huvi sellise tänapäevase religioossete kaupade allika suhtes, esemete ja poodide osa vastu tänapäeva katoliiklaste elus. 
Tänapäevase Ameerika religiooni uurijad kohtavad oma välitöödel tihti näiteid sellisest «pühitsetud materiaalsusest» (O'Connor 1994) mitte ainult kristlikes ja kristluse poolt mõjutatud kogukondades, vaid ka mittekristlaste seas. Sellised kogukonnad on näiteks roomakatoliiklased, ortodoksid, luterlased, mormoonid, nelipühilased, evangeelsed kristlased, afrokariibid, judaistid, moslemid, budistid, Ameerika pärismaalased, uuspaganad/wiccalased, newage'lased. Uurijad võivad küll leida, et materiaalsete objektide pühitsetusel on religioossetes süsteemides tugev jõud, kuid nad ei oska seda defineerida. Iga kultuur ja religioosne süsteem sõnastab omaenda uskumused pühitsetud esemete ja neisse uskumise vormi kohta.

Roomakatoliikluses kasutatakse unikaalset teoloogilist terminit, mis väljendab püha ja materiaalse suhet - sakramentaalsus (Hufford 1987). Sakramentaalsust on kirjeldatud kui «nägemust, et $\mathrm{kog} u$ reaalsus on potentsiaalselt ja tegelikkuses jumala kohaloleku kandja ja meie heaks toimiva jumaliku tegevuse instrument» (McBrien 1994: 1250). Sakramentaalsuse printsiip kinnitab, «et nähtamatu ja spirituaalne jumal on kohal nähtava ja materiaalse kaudu, mis omakorda muutuvad selle kohaloleku kaudu pühaks» (McBrien 1987: 441; vt ka Greeley 1988, 1989, 1990; Tracy 1981). Usklikele katoliiklastele eksisteerib unikaalne religioosne materiaalne kultuur, mis tugevdab sakramentaalsuse ligitõmmet katoliiklusele ning katoliiklastele meeldivate sakramentaalide ehk materiaalsete objektide suhtes, mis aitavad palves või pühendumuses.

Mis tüüpi sakramentaalid mingit konkreetset katoliiklast huvitavad, sõltub nende isiklikust usust ja usupraktikast, katoliikluse perekondlikust või etnilisest tüübist, milles nad on üles kasvanud, mida neile on katoliiklusest õpetatud, ja kohast või piirkonnast, kus nad elavad. Terminit sakramentaalne kasutatakse katoliiklaste poolt, et tähistada kirikus leiduvat individuaalset loomingut: liturgilisi kunstiteoseid (nagu nt altarid, altarikarikad, kirikurõivad, monstrantsid, paasaküünlad) või kirikudekoratsioone (nagu nt raidkujud, seinamaalingud ja freskod ning aknavitraazhid). Sakramentaalid tähendavad ka objekte, mida kasutatakse igapäevastes liturgiates (armulauavein, küünlad, viiruk). Sakramentaalid võivad tähendada samuti materiaalset kultuuri, mis on osa katoliiklaste isiklikust pühendumuslikust elust - kodu jaoks mõeldud maale ja kujusid, aga ka kaasaskandmiseks mõeldud asju, nagu reliikviad, palvehelmed, medalid, skapulaarid, krutsifiksid, pühapildid, religioossed ehted.

Esimeste Ameerikas avatud religioossete kaupluste ajalugu, kus müüdi Euroopast imporditud või kohapeal valmistatud esemeid, tuleb veel kirjutada. Aga teadaolevalt tõid misjonärid ja Euroopas koolitatud vaimulikud endaga kaasa esemeid Euroopa poodidest ja kloostrite töökodadest. Selleks on näiteks pühapildid, mille piiskop John Neumann, nüüdseks kanoniseeritud ja Philadelphiasse maetud pühak, tõi Põhja-Ameerikasse Böömimaalt. Ameerika religiooniajaloolased Ann Taves ja Colleen McDannell on märkinud, et enne kodusõda pärinesid Ameerika katoliiklaste põhilised hardusraamatud ja religioossed esemed (palvehelmed, skapulaarid, kujukesed ja pühapildid) kaubareisijate ja rändkaupmeeste käest, kellest osa olid juudid ning kes «käisid mööda katoliiklikke kodusid, koole ja kirikuid» (Taves 1986: 10). Katoliikliku elanikkonna kasvades, 1890. aastatel hakkasid katoliiklikud kirjastajad, kes olid levitanud oma kaupu rändkaupmeestele ja kihelkonna misjonitele, oma tegevust laiendama. Sellised kompaniid, nagu D. and J. Sadlier'i ja P. J. Kenedy and Sons New Yorgis, Benzinger Brothers Cincinnatis, Krieg Brothers Indianapolises ja Herder Company St. Louisis, pakkusid kohalikele poodidele suures valikus katoliiklikke materjale. Mitmesuguste religioossete kaupade tootmine laienes, kuna institutsiooniline hierarhia propageeris isiklikku vagadust, näiteks pühendumist Jeesuse pühale südamele ja roosikrantsile (McDannell 1995: 167-173; Taves 1986: 21-45). Seda stimuleeris ka Ameerika katoliiklike pühapäevakoolide süsteemi arenemine, mille tulemusena suurenes nõudlus raamatute ja esemete järele, et 
kinnistada katekismuse tundides õpitut, ja vajadus suunata katoliiklike immigrantide laste usuelu. Viktoriaanlik suundumus täita ameeriklaste kodud esemetega, mis kasvataksid kristlikku usku ja väärtusi, aitas sellele protsessile veelgi kaasa (McDannell 1986: 66; 1989; 1992; 1995). Selline praktika oli aga ka loomulik ülekanne ja evolutsioon Euroopa katoliiklikest kodudest, kus oli sajandeid olnud oma «pühasid nurkasid» (Milspaw 1986).

Üks vanemaid religioossete kaupade poode Philadelphias oli «Kilneri kirikukaubad», mis avas uksed Marketi tänaval 1888. aastal ja sulges need 1986. aastal Archi tänaval linnaelanike ostmistavade muutumise tõttu. Archi tänaval oli kauplus ümbritsetud pornograafiat müüvatest poodidest. Asutatud Isaac Kilneri poolt Baltimore'is põhiliselt usukirjanduse poena, jäi see viimaseks religioossete tarvete kaupluseks alal, kus neid varem oli olnud viis. Kilneril oli isegi Padua Püha Antoniuse reliikvia koos selle ehtsust tunnistava pitseeritud dokumendiga 1953. aastast ja sissekäiku märkiv pühaku kuju. Inimesed palvetasid aeg-ajalt selle juures või jätsid kuju juurde kirju palvesoovidega. Sellised religioossete kaupade poed, nagu Kilneri oma, on kasumit tootvad ärid, mis ei müü reliikviaid, erinevalt näiteks kauplusest, mis on seotud Püha John Neumanni pühamuga Philadelphias. Seal saavad usklikud pühaku klaaskirstus lebavale kehale austust avaldada (Kruesi 1995). Kilneri poe puhul oli reliikvia ukse juurde paigutamise põhjuseks Archi tänavale asukoha saamiseks pühakule antud tõotus. See reliikvia (mida loetakse «esimese klassi reliikviaks», sest tegemist on pühaku säilmetega) andis külastajale erilise tunde, et kogu pood on sakramentaalne. Ma mäletan iseennast 1960ndate lõpus lapsena sisenevat sellesse puupõrandaga ja kenasti vaatamiseks väljapandud asjade ning raamatutega poodi. See meenutas mulle oma atmosfääri poolest kiriku sakraalsust, mille ma tundsin ära, sest olin olnud altaripoiss. Seetõttu olin ka kõige suhtes, mida ma poes katsusin, väga ettevaatlik. Kopituslõhn ja hämar valgus lisasid jõudu tundele, et oled sisenenud ühte Philadelphia paljudest tegutsevatest sajandivahetuse kirikutest. Pood oli ehitud niisamuti nagu Philadelphia kirikud: reliikvia, kujud, pildid altari jaoks, küünlad. Puudusid ainult lilled.

«Kilneri kirikukaupade» taga oli «õdede salong», kus ajastul, mil nunnad ei kasutanud avalikke WC-sid, oli ka väike köök, külmkapp ja puhketuba mõne sohvaga. See oli Phildelphia peapiiskopkonnas üks väheseid kohti, kuhu nunnad võisid minna ja üksteisega mugavalt suhelda, samuti viia sinna külasolevaid naissugulasi laupäevadel ja päevadel, mil neil polnud õpetaja kohustusi klassitoas. Poeomanik pakkus neile kohvi, teed ja karastusjooke, toidu võtsid nad ise kaasa. Kuigi erinevatesse ordudesse kuuluvad nunnad kohtusid ja lävisid üksteisega kui Philadelphia pühapäevakoolide õpetajad, otsisid nad võimalust vestluseks pühitsetud materiaalsuse keskkonnas, kuid väljaspool piiskopkonnale kuuluvaid hooneid, eemal avalikkusest ja institutsionaalsest kirikust.

«Kilneri kirikukaupu» võib kirjeldada kui ühte paljudest 20. sajandi esimese poole kauplustest, kus müüdi asju, mida kutsuti «Barclay tänava kunstiks». See termin viitab Manhattani linnajaole, kus asusid Prantsusmaalt ja mujalt religioossete kaupade importijad, ning tegelikult «muutus sõimusõnaks raamatute ja asjade kohta, mis olid odavad, vulgaarsed ja ülevoolavalt jumalakartlikud» (McDannell 1995: 170). Usklikud naised mäletavad samal ajal Barclay tänavat kui katoliiklikku kultuurisümbolit. See äride kogum esindas katoliiklust Ameerikas kui elavat kultuuri, katoliikliku harduse ja koolide jõudu, kui nunnade olulist osa (suure arvu seal käivate õdede kaudu) religioosses Ameerikas.

Nii nagu Kilneri pood ja poed Barclay tänaval New Yorgis möödanikus, nõnda jätkab Püha Juuda pood institutsionaalse kiriku ja tema funktsionääride (preestrid, diakonid, õed jne), aga ka avalikkuse liturgiliste vajaduste teenindamist. Arvestatav osa selles jaekaubanduspoes on pühendatud ilmikute soovile omada religioosseid esemeid. Pärast poe avamist 1965. aas- 
tal asutasid Louis ja Norma DiCocco aegamisi teisi poode, samuti ka hulgi- ja jae-postimüügiärisid. 1990. aastate lõpus oli Püha Juuda pood üks kümnest suurimast kristlike religioossete kaupade müüjaist Ühendriikide mandriosas. Nende üle 500-leheküljeliste hulgimüügikataloogide levik ületas 10000 piiri, haarates põhiliselt idaranniku koole ja kirikuid. Jaemüügikatalooge levitasid nad umbes sama suure hulga. Pärast Louis DiCocco surma 1993. aastal on äri veelgi laienenud ning hõlmab ka internetikaubandust.

Havertowni Püha Juuda pood asub endises selvehallis, mis renoveeriti 1981. aastal 12000 ruutjala suuruseks kaubamajaks. Põhipood paikneb endise tagasihoidlikuma kivipoe, algse äri kõrval, mis müüb esimese armulaua jaoks kleite, loore ja ülikondi, samuti ka riietust muudeks juhtumiteks. Kreemikas stukatuurfassaad ja gooti stiilis raamistatud aknad lisati selle mahuka näituseruumi väliküljele 1996. aastal. Oma asukohtadelt aknalaudadel vaatavad kujud (näiteks 1,5-meetrine Püha Juudas) läbi selgete klaaside välismaailma. Sissepääsu juures pole Püha Antoniuse pühamu silti, kuid paremal pool peauksi on pronksist mälestustahvel poe asutaja kujutisega. Tahvlilt võib lugeda: «Louis R. DiCocco juuniori, Püha Juuda poe kaasasutaja mälestuseks. Kui ühe inimese läbi tuleb maailma natuke rohkem armastust ja headust, natuke rohkem valgust ja tõde, siis on selle inimese elul olnud mõte.»

Poe esiosa moodustab suur betoonlae, päevavalguslampide ja kulunud pruunika vaibaga kaubahall, laod ja väikesed kontorid on peidetud tahapoole. Keskelasuv kõrgem platvorm on ääristatud klaasriiulite ja väärtkaubavitriinidega, mis võimaldavad müüjatel jälgida vahekäike. See vihjab Teise Vatikani kirikukogu järgsele pühamule, kus kogudus istub ümber keskse liturgilise ruumi.

Püha Juuda poel puudub niisugune sakramentaalne õhkkond, mis iseloomustas minu lapsepõlve vanas stiilis usukaupade poode. Siiski teadsin ma kohe sellesse ruumi sisenedes, et olen katoliiklikus hoones - pood on täis topitud igasuguseid pühasid ja religioosseid asju, katoliiklikku kraami. Ma kohtasin seal tunnustust väärivat kogust sakramentaale, alates väikesest Püha Juuda pildist, mis on metallist välisukse külge kruvitud, kuni esimese armulaua tunnistuseni, mis on esiakende juures parempoolses vitriinis. Püha Juuda pood on keskus, mis võimaldab nii möödanikust pärinevate kui tänapäevaste isikliku vagaduse avalduste, kuid ka neid kasutavate katoliiklike sootsiumite vaatlemist ühes ja samas kohas. Siit võib leida müriaadi sakramentaalide esinemiskujusid, asju, mis ongi tehtud täiendamaks kiriku püha missiooni, aga samuti harilikke ilmalikke esemeid, millele on omistatud mingi spetsiifiline religioosne tähendus.

Asjad isiklikuks kasutamiseks või kinkimiseks on asetatud poe etteotsa ja kirikukaubad tahapoole. Sisenedes leiad end kohe paljude Püha Maarja kipsist, savist ja puust kujude, samuti raamitud trükipiltide juurest. Poe eesosa asustab suur hulk inglikujusid erinevates vormides: nukud, keraamika, raamitud pildid, klaasimaalid jne - tulenevalt ameeriklaste millenniumilõpu-vaimustusest nende spirituaalsete olendite vastu. Perekonna-teemalised kollektsioneerimisesemed nagu saksa «Hummelid» on teiste ilmalike kinkide (taldrikud, pehmed mänguloomad ja pildiraamid) seas.

Läbi vahekäikude liikudes näeb mingite kindlate teemade järgi organiseeritud väljapanekuid: inglid, konfirmatsioon, armulaud, pühakud, palvehelmed ja Maarja ilmutused. Siin võib leida asju, mis on tehtud katoliiklike siirderiituste ja tähtsate elusündmuste meenutuseks, nagu esimese armulaua ja konfirmatsiooni tunnistused, «esimese patukahetsuse» sõrmused ning kaitseingliga medalid vastsündinu voodi või käru jaoks.

Millal iganes sa lähed Püha Juuda poodi, vaatavad sulle vastu sajad silmad - meeldetuletus, et sa ei ole üksinda. Keskel asuvate müüjate juures on värvika näitusena suur hulk kõige eri- 
nevamates suurustes pühakute kujusid, alates Pühast Patrickust ja Pühast Frances Xavier Cabrinist kuni Püha Peregrinuse ja Püha Martin de Porresini. Lähedal on laialdane valik odavaid kolme kuni viie tolli pikkusi pühade isikute kujukesi, mida võib kutsuda katoliiklikuks plastitsiaanaks. Paremal seinal on pildid Jeesuslapsest, Jeesusest Kolmainsuse koosseisus, kannatavast Jeesusest, Jeesuse pühast südamest ja mitmed variandid, mida võiks nimetada Teise Vatikani kirikukogu Jeesuseks: naerev Jeesus, boheemlasest Jeesus ja minu lemmik jäähokit mängiv Jeesus. Nende piltide kõrval seisab rida kõigis suurustes kipskujusid, mis kujutavad Jeesust laps-kuningana, ja kujutis, mida katoliiklikus traditsioonis tuntakse kui Praha imikut. Üks või kaks riietekomplekti Jeesuse kui laps-kuninga kuju pühendumuslikuks riietamiseks saavad usklikud harilikult nende kujudega kaasa, kuid enamik kujusid poes on vaid valgetesse keraamilistesse rüüdesse riietatud.

Kogu ruumis on palju krutsifikse, riste, skapulaare, küünlaid, kirikuriideid, kuldseid ja hõbedasi medaleid taevase panteoni kujutistega, kipskujusid ja pilte väikestel kaartidel või plastikul. Suur hulk palvehelmeid annavad värvirikka pildi: muna-palvehelmed (s.t palvehelmed, mis on plastikmuna sees), suured ja väiksed puust palvehelmed, kristallpalvehelmed, kümnendpalvehelmed (s.t kümnehelmeliste sektsioonidega); roosad, mustad, valged, sinised ja pimedas helendavast plastikust palvehelmed. Müügil on pühitsetud vee anumad, inglitega nagid võtmete riputamiseks ja kaitseingliga lülitid, samuti köögimagnetid, millele on madonna pilt peale kleebitud (ja pirniga magnetid, kuhu on kirjutatud «Jesus Power and Light»), ning Püha Juuda võtmehoidjad. Traditsiooniline ohutu reisimise patroon Püha Christophorus esineb siin magnetsiltidena autode, paatide ja jalgrataste jaoks. Ma leidsin ükskord 1960. aastatel trükitud kaardid televisiooni patrooni Püha Assisi Clara õnnistustega, mis olid mõeldud televiisori peale asetamiseks; onnnistatud neitsi Maarja lambid ja öölambid ning isegi pooleteise-dollarilised Maarja kuju hoidlad, mis on plastikust torpeedosse pistetud pühitsetud neitsi Maarja ja freudistliku analüüsija unistuse hübriid. (Psühhoanalüüsi katoliiklike sektide ja harude kohta vt Carroll 1986; 1989; 1992; 1996). Mõned esemed näevad välja kui hoolikas käsitöö, kuid enamik on silmanähtavalt masstoodang.

Abordivastase liikumisega otseselt seotud asjad on kogutud vitriini poe keskkoha lähedal. Ilmekaks näiteks, kuidas traditsioonilisi kujutisi saab tänapäevaste jõudude poolt ära kasutada, on suur hulk Guadalupe jumalaema kujusid, mida müüakse tähistusega «sündimata laste Neitsi». Nimetatud Maarja ikoon, mis on Ameerika hispaania päritolu katoliiklastele nii tähtis, on omastatud abordivastaste katoliiklaste poolt nende liikumise sümboliks, ja seda traditsioonilise interpretatsiooni tõttu, et Maarja tundub sellel kujul olevat rase (Elizondo 1995).

Lõpuks leidus selles poes isegi tänapäevane kommertsvastus kinnisvaraomanike huvile Püha Joosepi abistava väe vastu, mis on märgendatud kui «Püha Joosepi majamüügipraktika». Pakend sisaldab trükitud instruktsioone, palveid koos trükitud pildiga ning väikese leiba ja kannu hoidva Joosepi kuju. Paki tagaküljel on pilt mehest, kes oma maja taga midagi matab või üles kaevab.

Pood müüb asju, mis on mõeldud palvetamise jaoks, ja asju, mis on mõeldud muutmaks igapäevaelu pidevaks pühendumiseks. On saadaval esemeid kiriku, pühapäevakooli, katekismuseklassi ja katoliikliku kodu jaoks. Poe ühes osas leiduvad religioosse muusika lindistused, tervituskaardid, mängud, aga ka pühakute elulugudest tehtud dokumentaal- ja mängufilmid (näiteks Bernadette'i laul). Ruumi tagaosa on reserveeritud ornaatide, peekrite, pateenide, pudelikeste, joogianumate ja kellukeste jaoks. 
Teisel pool keskset müüjate asupaika on ka raamatud: piiblid ja jutluseraamatud, abivahendid religioosse hariduse andmiseks, värvimisraamatud, missaraamatud, palveraamatud, harduskirjandus, üksikud teaduslikud tekstid konservatiivsetelt katoliiklikelt autoritelt. Aga see ei ole raamatupood, mis müüb mõningaid religioosseid esemeid, vaid religioossete asjade pood, mis müüb ka raamatuid ja broÜüüre. Siit võib leida Teise Vatikani kirikukogu materjale, Thomas Mertoni ja Pierre Teilhard de Chardini teoseid, paavsti ringkirju, siin on ka populaarseid hardusraamatuid Neitsi Maarja ilmutustest Lourdes'is, Fátimas, Garabandalis ja Medjugorjes, aga kõrvale on jäetud Bayside'i Jumalaema (Cuneo 1997: 175-194; Wojcik 1997: 60-97).

See pood esindab üldist Ameerika katoliiklikku materiaalset kultuuri, mis on endasse sulatanud vanemaid etnilisi uskumusi ja kujutisi. Püha Juuda pood suhtub katoliiklastesse kui ühtsesse Ameerika etnilisse gruppi, mitte kui ühte konkreetsesse etniliste katoliiklaste gruppi. Ta peegeldab eriti pärast Teist maailmasõda toimunud katoliikluse homogeniseerumist ja rahvuslikustumist, kui jõukus ja etniliste piirkondade lagunemine põhjustas muutuse katoliiklikes hinnangutes iseenda ja elukoha kohta (Fish 1982; Santino 1982). Protestantismi või konfessioonide-välise kristlusega seotud materiaalse kultuuri omaksvõtmine on märgatav teatavate piltide, näiteks Palvetavad käed, Hea karjane või Warner Sallmani Kristuse pea või Kristus ukse juures puhul, aga samuti sõnakesksete plakatite ja teiste sarnaste objektide kohalolus (Lippy 1994: 185; Williams 1989: 141-142). Mingi sobiva kirjutise, palve, piiblilõiguga ehitud asjad on osa kristlikust sõnade kujutisteks transformeerimise praktikast.

Pühakirjakohtadel põhinevaid pilte ja sõnalise teksti kaunistamist on kultiveerinud paljud kogukonnad, näiteks Pennsylvania sakslased, kelle kaunistatud käsikirjakunsti kutsutakse fraktuuriks. Siiski võib küsida, mis on primaarne - kas sõnad ise või pildid, mida nad loovad? Nii katoliiklased kui protestandid on olnud kujutiste suhtes mõistvad, kui tahes vastupidised õpetuslikud seisukohad ka eksisteerivad reformatsioonist alates. Morgan (1993, 1996, 1998) viitab Warner Sallmani populaarset protestantlikku religioosset kunsti käsitledes Ameerika protestantide memoraatidele (esimese isiku jutustused üleloomulikkusest), mis räägivad imelistest kogemustest seoses selle kunstniku kuulsa Kristuse peaga. Aga ta rõhutab ka, et Sallmani sihiks oli «kontrollida Piibli teksti sõnasõnalist loomust» (Morgan 1993: 43). Uue Testamendi lugude mehhaaniline reprodutseerimine Sallmani töödes «on selleks, et tekstualiseerida pühapilti ja teha see protestantidele seeläbi vastuvõetavaks à Protestandid tunnevad ennast kindlalt, lugedes Kristuse pilti» (Morgan 1993: 43; 1998).

Katoliiklased tunnevad ennast kindlalt, nähes Kristuse, Püha Maarja ja pühakute pilte. Jääb faktiks, et pildid on Püha Juuda poe alustoeks. Pood esindab Teise Vatikani kirikukogu eelset katoliiklikku arusaamist sakramentaalsest kultuurist, mis keskendub visuaalse ja sensuaalse loomulikele assotsiatsioonidele üleloomuliku ja pühaga. Kui üksikisikul on selline vastuvõtlikkus, siis ta ei loe pilti, vaid tunneb seda. Arusaam sellest, et pilti võib tunda, sellele emotsionaalselt vastata, on üks viis väljendada katoliiklust, see tähendab katoliikliku kogemuse afektiivset komponenti.

On täiesti mõistetav, et inimene, kes ei ole tuttav katoliikliku kultuuriga, küsiks Püha Juuda poe kohta: «Mis siin toimub? Mis pood see selline on? Mida see kõik tähendab?» See pood ise ja esemed, mida seal näidatakse, esindavad keerulisi «tähenduste, kasutusviiside, sümboolika ja seoste mitmeid tasandeid» (McAlister 1995: 306). Vaadates kõiki neid hardusesemeid ja usu artefakte, on võimalik näha ellu ärkamas reformatsiooni eriarvamusi vahendatud õnnistuse, puhastustule ja indulgentside ning usu või tegude järgi õigeksmõistmise kohta. See pood tähistab pinget rahvaliku vagaduse, mis rõhutab isiklikku lunastust, ning institutsionaalse kiriku kõikehõlmavuse vahel, mis on katoliikliku teoloogia oluline printsiip. 
Rahvausundi uurimise (Primiano 1995; 1997b), eriti Ameerika rahvakatoliikluse (mille all mõtlen mitte suurt hulka erinevaid etnilise või kultuurilise katoliiklikkuse avaldusi, vaid üksikute katoliiklaste usuelu vastavates kontekstides) uurimise jaoks on Püha Juuda pood oluline postmodernistlik müügipaik. Selles kohas võib näha peaaegu kõiki populaarseid pühi esemeid, mida katoliiklased kasutasid enne ja pärast Teist Vatikani kirikukogu.

Uurides Püha Thaddeuse rahvuspühamut, mis avati Chicagos 1929. aastal, märkis Robert Orsi, et «vagadus saavutas oma lae 1950. aastatel, vahetult enne Teist Vatikani kirikukogu» (Orsi 1989: 78). «Rahvavagadust» stimuleerisid eriti hardusperioodika, samuti ka «raadiopastorid ja prelaadid, katoliiklik kirjandus, katekismused, jutlused, usuõpetuse tunnid, raamatuklubid, moraali käsiraamatud jne» (Orsi 1994: 582; vt ka 1996: 14-18). See hõlmas nii immigrantide vagadusavaldusi kui ka «modernset algupärast immigratsiooni-järgset vagadust», mis «peegeldab immigrantide laste erinevates kohtades ja erineval ajal saadavaid kogemusi; see kõik ei asendanud lihtsalt vanemaid vagaduse vorme, vaid laiendas, täiendas ja (mõnel juhul) kujundas nad ümber» (Orsi 1991: 219).

Postmodernse Ameerika katoliku kogukonna tunnuseks on jagunemine selle alusel, kas hardusesemete kasutamine on vajalik, parandamaks isiklikku vagadust. Alates 20. sajandi liturgilisest liikumisest (Searle 1995: 783-785; White 1995: 115-140), kuid eriti pärast Teise Vatikani kirikukogu reforme (vt 1963. aasta liturgia pidamise seadust) on institutsionaalne kirik teinud tõsiseid pingutusi lõpetamaks kogudusepoolset paraliturgilist tegevust liturgia ajal (näiteks roosikrantsiga palvetamine jms palvused). Eesmärgiks on elavam osavõtt Paulus VI reformeeritud missast, mida peetakse vastava regiooni rahva keeles (White 1995: 115-140). Nii missa ajal kui muidu on sellised isiklikud sakramentaalid, nagu roosikrants, palveraamatud ja pühapildid nüüd vähem tähtsustatud. Sakraalset materiaalsust ei ole loomulikult roomakatoliiklusest eemaldatud (vt Catechism of the Catholic Church 1994: 16671669), kuid selle tähtsuse katoliiklikus vagadusliikumises seadis institutsionaalne kirik kahtluse alla. Kirikukogu dokumendid ja hilisemad institutsionaalsed kirjutised juhivad vaimulikke ja ilmikuid nägema sakramentaalsete esemete funktsiooni pühaduse väljendamises, eriti rituaalides, aga mitte pidama neid iseenesest pühadeks. Nii näiteks pole viiruk, küünlad, riietus, monstrants, armulaualeib iseenesest tähtsad asjad, vaid loeb nende holistiline toime, tõstmaks liturgia tähtsust, tõsidust ja palve täiuslikkust. Need esemed peavad olema kvaliteetsed sellepärast, et neid kasutatakse tähtsates sakraalsetes tseremooniates, mitte sellepärast, et nad on iseenesest tähtsad. Samasugune mõtlemine seondub ka isikliku vagadusega: mitte pühakukuju või reliikvia või pühapilt ise pole palve juures tähelepanu keskmes, vaid see, kuidas need sakramentaalsed asjad aitavad parandada jumalale suunatud palve kvaliteeti.

20. sajandi lõpus on Ameerika katoliiklased mõttes ja teos jagunenud religioossetesse esemetesse suhtumise järgi. Konservatiivsed ja restauratsioonilised katoliiklased on säilitanud rohkem esemetele orienteeritud subjektiivset sakramentalismi, samal ajal kui progressiivsed katoliiklased toetavad rohkem holistlikku ja relatsioonilist suhtumist religioossetesse objektidesse. On võimatu vaadelda Teise Vatikani kirikukogu järgset Ameerika katoliiklust, märkamata erinevusi traditsioonides, kvaliteedis ja stiilis, mis valitsevad Ameerika Ühendriikide erinevate piirkondade institutsionaalselt sponsoreeritud ning samuti ilmalikus praktikas. Näiteks on idaranniku piiskopkondade kogudused säilitanud konservatiivsema suhtumise katoliiklusesse kui kesklääne omad. See fenomen võib olla seotud üldise kultuurilise formaalsusega idas või konkreetsete etniliste gruppidega, kes sinna elama asusid. Progressiivsete katoliiklaste jaoks on religioossete esemetega täidetud Püha Juuda pood vagaduse mineviku anakronism, traditsiooni nähtav külg, mis ei räägi midagi selle tänapäevasest reaalsusest. 
Teiste kogukondade, näiteks traditsiooniliste katoliiklaste või Kariibi mere afrokariibi sünkretistlike religioonide, sh voodoo ja santeria liikmete silmis esindab see pood ja tema sisu katoliiklaseks olemist - osavõttu maagilis-müstilisest religioonist, kus asjad peegeldavad ning omavad püha ja üleloomulikku jõudu. Irooniliselt väljendudes võib selles poes suvalisel ajal olla tähelepanuväärselt erinevaid kliente, kes kõik esindavad 20. sajandi Ameerika katoliiklikku kirikut: kihelkonnapreestrid ja linnakirikute vaimulikud, kes ostavad oma kiriku jaoks tarbeid; koduperenaised, kes valmistuvad omaenda kodupalvusteks; mambod, kes ostavad oma voodoo-tseremoonia jaoks mõnda vajalikku eset, mida kohalikus botanicas polnud, ja vanaemad, kes ostavad esimesel armulaual käinutele kinke. See kauplus teenindab tänapäevast Ameerika katoliiklikku kogukonda kogu tema üllatavas varieeruvuses.

Püha Juuda pood kehastab endas huvitavaid igandeid, aktiivset loomingut, teisitimõtlemise impulsse, läbielatud kogemuste peegeldusi ja passiivseid kohandumisi, mis märgivad rahvausundi pidevat tagasiimbumist igapäevaellu (Primiano 1995). Seal müüdavaid esemeid kasutab võimas suunav kirik, loomaks endale lojaalset usklike kogukonda, ning ka jõukad isikud, kellel on omaenda loovad ja isiklikud jumalakogemused.

Paljusid selles poes müügil olevaid asju klassifitseeriksid isegi katoliiklased ei millekski enamaks kui katoliiklikuks kitshiks, religioosseks rämpsuks, millel pole mingit vaimset väärtust ja mis on maitsetud. Selline määratlus annab hinnangu nende inimeste usule, kes sellest poest ostavad. Katoliikliku kultuuri sakramentaalse iseloomu tõttu on kõigil esemetel potentsiaal saada usuobjektiks. Selline materiaalne kultuur sunnib õpetlasi ümber hindama limiteerivat märgendit kitsh, mida defineeritakse kui «pseudokunsti, mis on tihti mõeldud massitarbimiseks..., mõeldud rahuldama laia publiku kõige pinnapealsemaid esteetilisi vajadusi ja tujusid...» (Calinescu 1987: 262; vt ka McDannell 1995: 163-167). Termin «katoliiklik kitsh» tähistab pigem keerulist sulamit tundepuhangutest ja rõõmust katoliikluse etniliste, regionaalsete ning rahvuslike aspektide absurdsest või skandaalsest avaldumisest Ameerika kontekstis. Et mõista, miks need objektid on tundepuhangute aluseks ja milles avaldub nende mõttekus, tuleb mingil määral osa saada kultuuriväärtustest, mida esindavad näiteks Püha Lucia kuju, kes hoiab käes taldrikut silmadega, ohtralt verd jooksvad stigmaatikud või «mittekõdunevate» pühakute mumifitseerunud kehad, mida hoitakse sajandite kaupa kõrvalaltaritel. See on niimoodi sõltumata sellest, kas tegemist on rahvakunsti, rahvaliku kunsti, kõrgkunsti või kitshiga. Sellised poed loovad võimaluse Ameerika katoliikliku rahvausundi rikkalikuks etnograafiliseks eksponeerimiseks. Nad märgivad muutust - võiks öelda, et murrangut - visuaalses, kombatavas, kuuldavas ja maitstavas katoliiklikus kogemuses enne ja pärast Teist Vatikani kirikukogu.

Vaadates selle katoliikliku varamu peale, ei näe ma üksnes institutsionaalselt sanktsioneeritud eestkoste vahendamise, meditatsiooni ja sakramentaalsuse teoloogilisi printsiipe, vaid ka palju sügavamat tähendust: rahvausundi sanktsiooni sellele, kuidas inimesed ise jätkavad isegi kõige tähtsusetuma igapäevaellu kuuluva sakramentaliseerimist. Oma aja veetmine Püha Juuda poes ei tähenda üksnes kohtumist Püha Joosepi, Neitsi Maarja ja teiste «katoliiklike sõprade» kujudega, vaid ka erinevais vormides avaldunud iidse inimliku kalduvusega esemestada oma jumalaid ja otsida õnnistust iseendale ning meid ümbritsevale maailmale.

Ma ostsin ühe odava Püha Joosepi kuju ja saatsin oma õpilase isale. Ta mattis selle õpetuste kohaselt maha ja kuus kuud hiljem müüs oma maja ära. Plastikkuju, mida ma otsisin kogu katoliiklikust Philadelphiast, seisab tema New Foundlandi kodu söögitoas.

Tõlkinud Sander Vesik 


\section{Kommentaarid}

1. Raamatust Perspectives on American Religion and Culture. Peter W. Williams (toim.). Massachusetts-Oxford: Blackwell Publishers Inc. 1999.

\section{Kirjandus}

Adler, Margot 1986. Drawing Down the Moon. Boston, Massachusets: Beacon Press.

Borrello, Mary Ann \& Mathias, Elizabeth 1977. Botanicas: Puerto Rican folk pharmacies. Natural History, 1986/7, lk 64-73.

Briggs, Charles L. 1989. The Woodcarvers of Córdova, New Mexico: Social Dimensions of an Artistic «Revival». Albuquerque, New Mexico: University of New Mexico Press.

Brown, Peter 1981. The Cult of the Saints: Its Rise and Function in Latin Christianity. Chicago: University of Chicago Press.

Calinescu, Matei 1987. Five Faces of Modernity. Durham, NC: Duke University Press.

Carroll, Michael P. 1986. The Cult of the Virgin Mary. Princeton, New York: Princeton University

Press.

Carroll, Michael P. 1989. Catholic Cults and Devotions: A Psychological Inquiry. Kingston, Ontario: McGill-Queen's University Press.

Carroll, Michael P. 1992. Madonnas that Maim: Popular Catholicism in Italy Since the Fifteenth Century. Baltimore: Johns Hopkins University Press.

Carroll, Michael P. 1996. Veiled Threats: The Logic of Popular Catholicism in Italy. Baltimore: Johns Hopkins University Press.

Cartwright, Christine A. 1981. Indian Sikh homes out of North American houses: mental culture in material translation. New York Folklore 7, lk 97-111.

Catechism of the Catholic Church 1994. New York: Paulist Press.

Clark, Robin 1990. Another sale! by St. Joseph. Philadelphia Inquirer, September 23, $1 \mathrm{k} 1$.

Cooper, Martha \& Sciorra, Joseph 1994. R. I. P. Memorial Wall Art. New York: Henry Holt.

Constitution on the Sacred Liturgy 1966. Documents of Vatican II. New York: Guild Press.

Cosentino, Donald J. (toim.) 1995. Sacred Arts of Haitian Vodou. Los Angeles: UCLA Fowler

Museum of Cultural History.

Cuneo, Michael W. 1997. The vengeful Virgin: case studies in contemporary American Catholic

apocalypticism. Thomas Robbins \& Susan J. Palmer (toim.) Millennium, Messiahs, and Mayhem:

Contemporary Apocalyptic Movements. New York: Routledge, lk 175-94.

Dewhurst, C. Kurt \& MacDowell, Betty \& MacDowell, Marsha 1983. Religious Folk Art in America: Reflections of Faith. New York: E. P. Dutton.

Dillenberger, John 1984. The Visual Arts and Christianity in America: The Colonial Period through the Nineteenth Century. Chico, California: Scholars Press.

Durand, Jorge \& Massey, Douglas S. 1995. Miracles on the Border: Retablos of Mexican Migrants to the United States. Tucson, Arizona: University of Arizona Press.

Elizondo, Virgilio (1995). Our Lady of Guadalupe. Richard P. McBrien (toim.) The Harper Collins Encyclopedia of Catholicism. San Francisco: HarperSanFrancisco, lk 594-596.

Fish, Lydia 1982. Ethnicity and Catholicism. New York Folklore 8, 1k 83-92.

Flores-Peña, Ysamur \& Evanchuk, Roberta J. 1994. Santería Garments and Altars: Speaking Without a Voice. Jackson, Miss.: University of Mississippi Press. 
Giffords, Gloria Fraser 1992. Mexican Folk Retablos. Albuquerque, New Mexico: University of New Mexico Press.

Gizelis, Gregory 1971. The use of amulets among Greek Philadelphians. Pennsylavnia Folklife 20/3, 1k 30-37.

Greeley, Andrew M. 1988. God in Popular Culture. Chicago: Thomas More Press.

Greeley, Andrew M. 1989. Protestant and Catholic: is the analogical imagination extinct? American Sociological Review 54, 1k 485-502.

Greeley, Andrew M. 1990. The Catholic Myth: The Behavior and Beliefs of American Catholics. New York: Charles Scribner's Sons.

Halle, David 1993. Inside Culture: Art and Class in the American Home. Chicago: University of Chicago Press.

Hufford, David J. 1987. The love of God's mysterious will: suffering and the popular theology of healing. Listening 22, 1k 225-239.

Kalb, Laurie Beth 1994. Grafting Devotions: Tradition in Contemporary New Mexico Santos. Albuquerque, New Mexico: University of New Mexico Press.

Kruesi, Margaret 1995. Symptoms, signs and miracles: narratives of illness and healing at the St. John Neumann Shrine. Philadelphia, Pennsylvania. Ph.D. dissertation, Department of Folklore and Folklife, University of Pennsylvania, Philadelphia.

Lange, Yvonne 1974. Lithography, an agent of technological change in religious folk art: a thesis. Western Folklore 33/1, lk 51-64.

Lepovitz, Helena Waddy 1991. Images of Faith: Expressionism, Catholic Folk Art, and the Industrial Revolution. Athens, Ga.: University of Georgia Press.

Lessard, Pierre 1981. Les Petites Images dévotes. Quebec: Presses de l'Universite Laval. Lippy, Charles H. 1994. Being Religious, American Style: A History of Popular Religiosity in the United States. Westport, Connecticut: Greenwood Press.

McAlister, Elizabeth 1995. A sorcerer's bottle: the visual art of magic in Haiti. Donald Consentino (toim.). Sacred Arts of Haitian Vodou. Los Angeles: UCLA Fowler Museum of Cultural History, lk 304-321.

McBrien, Richard P. 1987. Roman Catholicism. Mircea Eliade (toim.). The Encyclopedia of Religion, vol. 12, New York: Macmillan, lk 429-45.

McBrien, Richard P. 1994. Catholicism. San Francisco: HarperSanFrancisco.

McDannell, Colleen 1986. The Christian Home in Victorian America, 1840-1900. Bloomington, Indiana: Indiana University Press.

McDannell, Colleen 1989. Catholic domesticity, 1860-1960. Karen Kennelly, CSJ (toim.). American Catholic Women: A Historical Exploration. New York: Macmillan, 1k 48-80.

McDannell, Colleen 1992. Parlor piety: the home as sacred space in Protestant America. Jessica H. Foy \& Thomas J. Schlereth (toim.). American Home Life, 1880-1930: A Social History of Spaces and Services. Knoxville, Tennessee: University of Tennessee Press, 1k 162-189.

McDannell, Colleen 1995. Material Christianity: Religion and Popular Culture in America. New Haven, Connecticut: Yale University Press.

Milspaw, Yvonne J. 1986. Protestant home shrines: icon and image. New York Folklore 12/3-4, lk 119-136.

Morgan, David 1993. Imaging Protestant piety: the icons of Warner Sallman. Religion and American Culture 3, lk 29-47.

Morgan, David (toim.) 1996. Icons of American Protestantism: The Art of Warner Sallman. New Haven, Connecticut: Yale University Press.

Morgan, David 1998. Visual Piety: A History and Theory of Popular Religious Images. Berkeley, California: University of California Press. 
Murphy, Joseph M. 1988. Santería: An African Religion in America. Boston, Massachusets: Beacon Press.

O'Connor, Kathleen Malone 1994. The alchemical creation of life (Takwin) and other concepts of genesis in medieval Islam. Ph.D. dissertation. Department of Religious Studies, University of Pennsylvania, Philadelphia.

Orsi, Robert Anthony 1985. The Madonna of 115th Street, Faith and Community in Italian Harlem. New Haven, Connecticut: Yale University Press.

Orsi, Robert Anthony 1989. What did women really think when they prayed to St. Jude? U.S. Catholic Historian 8, 1k 67-79.

Orsi, Robert Anthony 1991. The center out there, in here, and everywhere else: the nature of pilgrimage to the shrine of St. Jude, 1929-1965. Journal of Social History 25, 1k 213-32.

Orsi, Robert Anthony 1994. 'Mildred, is it fun to be a cripple?': the culture of suffering in midtwentieth century American Catholicism. South Atlantic Quarterly 93, 1k 547-590.

Orsi, Robert Anthony 1996. Thank You, Saint Jude: Women's Devotion to the Patron Saint of Hopeless Causes. New Haven, Connecticut: Yale University Press.

Pacelle, Mitchell 1990. Some people will try anything except lowering the asking price. Wall Street Journal, September 17.

Pocius, Gerald L. 1986. Holy pictures in Newfoundland houses: visual codes for secular and supernatural relationships. Peter Narváez \& Martin Laba (toim.). Media Sense: The Folklore Popular Culture Continuum. Bowling Green, Oh.: Bowling Green University Popular Press, lk 12448.

Primiano, Leonard Norman 1995. Vernacular religion and the search for method in religious folklife. Western Folklore 54, lk 37-56.

Primiano, Leonard Norman 1997a. Folklife. Thomas A. Green (toim.). Folklore: An Encyclopedia of Beliefs, Customs, Tales, Music and Art. Santa Barbara, Calif.: ABC-Clio lk 322-331.

Primiano, Leonard Norman 1997b. Folk religion. Thomas A. Green (toim.). Folklore: An Encyclopedia of Beliefs, Cutoms, Tales, Music and Art. Santa Barbara, California: ABC-Clio, lk 710-717.

Santino, Jack 1982. Catholic folklore and folk Catholicism. New York Folklore 8, lk 93-106.

Sciorra, Joseph 1989. Yard shrines and sidewalk altars of New York's Italian-Americans. Thomas

Charter \& Bernard L. Herman (toim.). Perspectives in Vernacular Architecture, vol. III, Columbia, Missouri: University of Missouri Press, lk 185-198.

Sciorra, Joseph 1993. Multivocality and vernacular architecture: the Our Lady of Mount Carmel Grotto in Rosebank, Staten Island. Luisa Del Giudice (toim.). Studies in Italian American Folklore. Logan, Utah: Utah State University Press, 1k 203-243

Searle, Mark 1995. Liturgical Movement. Richard P. McBrien (toim.). The Harper Collins

Encyclopedia of Catholicism. San Francisco: HarperSanFrancisco, 1k 783-785.

Shaner, Richard H. 1961. Living occult practices in Dutch Pennsylvania. Pennsylvania Folklife 12/3, 1k 62-63.

Shaner, Richard H. 1972. Recollections of witchcraft in the Oley Hills. Pennsylvania Folklife 21, Folk Festival Supplement, lk 39-43.

Spamer, Adolf 1930. Das Kleine Andachtsbild vom XIV. bis zum XX. Jahrhundert. München:

Bruckmann.

Taves, Ann 1986. The Household of Faith: Roman Catholic Devotions in Mid-Nineteenth-Century America. Notre Dame, Indiana: Notre Dame University Press.

Teske, Robert Thomas 1973. The Eikonostasi among Greek-Philadelphians. Pennsylvania Folklife 23/1, 1k 20-30. 
Teske, Robert Thomas 1980. Votive Offerings among Greek Philadelphians: A Ritual Perspective. New York: Arno Press.

Teske, Robert Thomas 1985. Votive offerings and the belief system of Greek-Philadelphians.

Western Folkore 44, 1k 208-224.

Tracy, David 1981. The Analogical Imagination. New York: Crossroad.

Turner, Kay Frances 1982. Mexican American home altars: towards their interpretation. Aztlan: International Journal of Chicano Studies Research 13/1-2, 1k 309-326.

Turner, Kay Frances 1983. The cultural semiotics of religious icons: La Virgen de San Juan de los Lagos. Semiotica 47, lk 317-361.

Turner, Kay Frances 1990. Mexican-American women's home altars: the art of relationship. Ph.D. dissertation. Department of Anthropology, University of Texas, Austin.

Turner, Kay \& Seriff, Suzanne 1987. Giving an altar: the ideology of reproduction in a St. Joseph's Day feast. Journal of American Folklore 100, 1k 446-460.

Vlach, John Michael 1989. Morality as folk aesthetic. Robert E. Walls \& George H. Schoemaker (toim.). The Old Traditional Way of Life: Essays in Honor of Warren E. Roberts. Bloomington, Indiana: Trickster Press, lk 28-39.

White, James F. 1995. Roman Catholic Worhship: Trent to Today. New York: Paulist Press. Williams, Peter W. 1988. Religious architecture and landscape. Charles H. Lippy \& Peter W. Williams (toim.). Encyclopedia of the American Religious Experience, vol. III, New York: Charles Scribner's Sons, lk 1325-1339.

Williams, Peter W. 1989. Popular Religion in America: Symbolic Change and the Modernization of Process in Historical Perspective. Urbana, Illinois: University of Illinois Press.

Williams, Peter W. 1997. Houses of God: Region, Religion, and Architecture in the United States. Urbana, Illinois: University of Illinois Press.

Wojcik, Daniel 1997. The End of the World as We Know It: Faith, Fatalism, and Apocalypse in America. New York: New York University Press.

Yoder, Don 1988. Fraktur: an introduction. Pennsylvania German Fraktur and Printed Broadsides: A Guide to the Collections in the Library of Congress. Washington DC: Library of Congress, 1k 919. Reprint 1990 Don Yoder (toim.). Discovering Amerian Folklife: Studies in Ethnic, Religious, and Regional Culture. Ann Arbor, Michigan: UMI Research Press, lk 271-281.

Yoder, Don 1990. The Picture-Bible of Ludwig Denig: A Pennsylvania German Emblem Book. New York: Hudson Hills Press.

Yoder, Don \& Graves, Thomas E. 1989. Hex Signs: Pennsylvania Dutch Barn Symbols and their Meaning. New York: E. P. Dutton. 